\title{
Biochemical Changes of Glutathione S-Transferase Activity During the Germination of Trifolium alexandrinum
}

\author{
Ragaa Reda Hamed ${ }^{1}$, Ehab Mostafa Mohamed Ali ${ }^{2}$, Abeer Shokeer,", Rasha Awni Guneidy ${ }^{1}$, \\ Abdul Aziz Mohamad Gad ${ }^{1}$ \\ ${ }^{1}$ Department of Molecular Biology, Genetic Engineering and Biotechnology Division, National Research Center, Cairo, Egypt \\ ${ }^{2}$ Biochemistry Division, Chemistry Department, Faculty of Science, Tanta University, Egypt
}

\section{Email address:}

abeergs70@hotmail.com (A. Shokeer)

\section{To cite this article:}

Ragaa Reda Hamed, Ehab Mostafa Mohamed Ali, Abeer Shokeer, Rasha Awni Guneidy, Abdul Aziz Mohamad Gad. Biochemical Changes of Glutathione S-Transferase Activity During the Germination of Trifolium alexandrinum. American Journal of Life Sciences.

Vol. 3, No. 4, 2015, pp. 257-267. doi: 10.11648/j.ajls.20150304.12

\begin{abstract}
The key objective of this study was to investigate the effect of germination on biochemical and enzymatic antioxidant activities of Trifolium alexandrinum seeds. The T. alexandrinum was chosen for GST purification and characterization due to its highest GST activity and antioxidant capacity, beside its economical importance. Seeds of $T$. alexandrinum were germinated for 6 days. Changes in glutathione S-transferase (GST), superoxide dismutase (SOD), catalase (CAT), glutathione reductase (GR) and glutathione peroxidase (GPx) in germinating and dormant seeds of T. alexandrinum were evaluated. Also the changes in the total phenolic and flavonoid contents as well as the antioxidant capacities were monitored for 6 days of germination using spectrophotometeric methods. Simple reproducible procedures for the purification of T. alexandrinum GST from both dormant and 6 days germinated seeds were established using DEAE-Sepharose and Sephadex G-100 columns chromatography. The results showed the presence of three isoenzymes for both dormant and germinated seeds designated as GST1, GST2 and GST3. The major GST of the dormant seed was GST2 while for the germinated one was GST3. Dormant GST2 was expressed as a heterodimer with molecular weight of 27.5 and $28.5 \mathrm{KDa}$ while germinated GST3 was expressed as a homodimer with molecular weight of $27 \mathrm{KDa}$. Characterization of both dormant GST1 \& GST2 and germinated GST2 and GST3 including optimum $\mathrm{pH}$, kinetic parameters $\left[\mathrm{k}_{\mathrm{m}}^{\mathrm{GSH}}\right.$ of $1.17 \pm 0.39,1.22 \pm 0.13,0.84 \pm 0.19$, $0.96 \pm 0.24 \mathrm{mM}$, respectively and $\mathrm{k}_{\mathrm{m}}{ }^{\mathrm{CDNB}}$ of $0.65 \pm 0.095,0.57 \pm 0.11,0.59 \pm 0.14,1.02 \pm 0.18 \mathrm{mM}$, respectively]. The substrate selectivity using different electrophilic compounds and inhibitor effects were carried out. In opposite to other isoenzymes, germinated GST3 exhibited enzymatic activity towards ethacrynic acid with specific activity of $0.073 \pm 0.005 \mu \mathrm{mol} / \mathrm{min} / \mathrm{mg}$ protein while cibacron blue was the most potent inhibitor for these isoenzymes.
\end{abstract}

Keywords: Antioxidant Enzymes, Inhibition, Kinetic Parameters, Seed Germination, Trifolium alexandrinum

\section{Introduction}

Plants, similar to animals, face several problems such as a need for regulation of metabolic processes, reproduction and efficient defense against enemies. They respond to a variety of environmental stresses (e.g. change in temperatures, drought, salinity, UV or ozone stress and pathogen infections) through the induction of antioxidant defense enzymes that provide protection against further damage [1].

Glutathione S-transferases (GSTs; EC 2.5.1.18) are a family of enzymes involved in detoxification of different xenobiotics. The main function of GST is to catalyze the conjugation of glutathione (GSH) to an electrophilic site of a broad range of potentially toxic and carcinogenic compounds, thereby making such compounds less biologically active and enabling their excretion [2]. In plants, all the GSTs described to date are dimmers composed of 25-30 kDa subunits. On the basis of sequence similarity and gene organization, plant GSTs appear to have evolved from a common ancestral GST into four distinct cytosolic classes, namely the Phi, Tau, Zeta, and Theta GSTs. The two largest classes are the plantspecific Phi and Tau GSTs. Both classes have major roles in herbicides detoxification [3]. In addition, plant GSTs have less well characterized roles in endogenous metabolism including functioning as glutathione peroxidases counteracting oxidative stress and also act as flavonoid- 
binding proteins, stress signaling proteins and regulators of apoptosis [4]. Plant GST has been concerned in the agricultural chemistry and biochemistry because of its major factors involved in the resistance of a variety of herbicides [5].

The plant, Trifolium alexandrinum (common name: Egyptian clover, berseem clover) represents the main forage crops for livestock and have produced milk and /or meat in Egypt [6] and its seeds are used as an antidiabetic treatment [7]. It is traditionally as human ailments, including renal dysfunctions [8]. The leaves, seeds and sprouts of $T$. alexandrinum also have medicinal use in many metabolic deficiencies, are phytonutrient-rich, provide significant amounts of antioxidants [9], delay the aging processes, help to strengthen the immune system, especially protect against infection, prevent heart disease and coronary heart disease (through decreasing plasma cholesterol) [10]. The $T$. alexandrinum contains two to three percent saponin glycosides and phenolic compounds [11]. Phytochemical investigations of $T$. alexandrinum have revealed the presence of terpenoind saponin, flavonoids, isoflavonoids, and fatty acids in different parts of the same plants.

Germination is one of the most common and effective processes for improving the quality of legumes [12]. Exposure to free radicals from a variety of sources has led organisms to develop a series of defense mechanisms [13]. Defense mechanisms against free radical-induced oxidative stress involve: (i) preventative mechanisms, (ii) repair mechanisms, (iii) physical defenses, and (iv) antioxidant defenses. Enzymatic antioxidant defenses include superoxide dismutase (SOD), glutathione peroxidase (GPx), catalase (CAT), and GST. Non-enzymatic antioxidants are represented by ascorbic acid (Vitamin C), $\alpha$-tocopherol (Vitamin E), glutathione (GSH), carotenoids, flavonoids, and other antioxidants [14].

Thus the key objective of this study was to investigate the effect of germination on biochemical and enzymatic antioxidant activities of $T$. alexandrinum seeds. The changes in the total phenolic and flavonoid contents as well as the antioxidant capacities were also monitored for 6 days of germination.

\section{Materials and Methods}

\subsection{Materials}

The dormant seeds of $T$. alexandrinum, Leguminosae family were collected from Agricultural Research Centre, ElDokki, Giza. The plants were identified and authenticated by the Department of Herbachium Botany at the National Research Center. The healthy seeds were selected and stored in sealed polyethylene bags with silica gel included as a desiccant for one week. The samples were kept in a refrigerator at $4^{\circ} \mathrm{C}$ until ready for extraction. 1-chloro-2, 4dinitrobenzene (CDNB), Folin-Ciocalteu's (FC) reagent, 1,1 diphenyl-2-picryl-hydrazyl (DPPH), nicotinamide adenine dinucleotide phosphate reduced form (NADPH), sulfobromophthaliene are products of Sigma-Aldrich Company. DEAE-Sepharose was obtained from GE Healthcare Co. The reduced GSH was obtained from BioBasic INC. Glutathione disulphide (GSSG) was purchased from Fluka Company.

\subsection{Determination of Total Phenolics}

The $T$. alexandrinum seeds $(0.5 \mathrm{~g})$ were gently powdered, homogenized and extracted with $70 \%$ ethanol at room temperature $\left(25^{\circ} \mathrm{C}\right)$. The total phenolics were determined by Folin-Ciocalteu's reagent method with some modifications of the method proposed by Singleton and Rossi [15]. The total phenolic content was determined as gallic acid equivalents (mg gallic acid / g dry seed).

\subsection{Determination of Total Flavonoids}

Total flavonoids were determined using the procedure reported by Woisky and Salatino [16]. Total flavonoids of the sample were expressed as catechin equivalents (mg catechin / g dry seed).

\subsection{Determination of Antioxidant Capacity}

The free radical scavenging activities were determined by DPPH method with some modifications of the method proposed by Blois [17]. DPPH free radical scavenging ability of the extract was expressed as $\mu \mathrm{g}$ ascorbic acid equivalents per gram dry seed.

\subsection{Seed Germination}

Sterile T. alexandrinum seeds were germinated in a growth chamber with a photoperiod of $16 \mathrm{~h}$ day/ $8 \mathrm{~h}$ night at $23 \pm 1^{\circ} \mathrm{C}$. Germinated seeds were firstly collected and then homogenized using mortar in $25 \mathrm{mM}$ Tris- $\mathrm{HCl}$ buffer, $\mathrm{pH} 7.5$. The homogenate was centrifuged at $11,000 \times \mathrm{g}$ for $30 \mathrm{~min}$ and the clear supernatant was designated as crude homogenate and saved at $-20^{\circ} \mathrm{C}$ for further analyses.

\subsection{Purification of GST from T. Alexandrinum Seeds}

Crude homogenate of the dormant and germinated seeds was incubated with DEAE-Sepharose for $30 \mathrm{~min}$, filtered, washed with $25 \mathrm{mM}$ Tris-HCl, pH 7.5 containing $10 \mathrm{mM}$ $\mathrm{CaCl}_{2}$ and $2 \mathrm{mM}$ DTT (buffer A) and then packed to the column $(8.5 \times 2.6 \mathrm{~cm}$ i.d.). The bound proteins were eluted with buffer A using step gradient of $\mathrm{NaCl}(0.05,0.1$ and 0.2 $\mathrm{M})$. Fractions in $3 \mathrm{ml}$ volume were collected at a flow rate of $60 \mathrm{ml} / \mathrm{h}$. The GST containing fractions under each peak were pooled separately and designated as GST1, GST2 and GST3 for dormant seeds and germinated GST1, GST2 and GST3 for germinated seeds according to their elution order and saved at $-20^{\circ} \mathrm{C}$ for further analyses. The purified DEAESepharose enzyme was applied to a Sephadex G-100 column $(85 \times 1.6 \mathrm{~cm}$ i.d. $)$ equilibrated with buffer $\mathrm{A}$ to estimate molecular weight [18]. Protein concentration was determined by the method of Bradford [19] using bovine serum albumin as a standard. 
Native- PAGE (12\%) was carried out using a horizontal electrophoresis system (Amersham Pharmacia). The gel was stained for GST activity and for protein with $0.1 \%(\mathrm{w} / \mathrm{v})$ Coomassie Brilliant Blue R250 (CBB R250) dissolved in $30 \%$ methanol and $10 \%$ glacial acetic acid. The subunit molecular weight of the pure enzyme was determined by SDS-PAGE (12\%) as described by Laemmli [20].

\subsection{Enzyme Assays}

\subsubsection{Glutathione S-Transferase}

The specific activities of the GST were measured towards CDNB, 4-nitrophenthyl bromide (NPB), 1,2-epoxy-3-[4nitrophenoxy]-propane (EPNP), ethacrynic acid (EA), and 1, 2 - dichloro-4-nitrobenzene (DCNB) according to the method described by Habig et al. [21]. The activity was measured with cumene hydroperoxide $(\mathrm{CuOOH})$ by coupling the glutathione reductase-dependent NADPH oxidation [22]. The activity was also measured with styrene oxide (SO) [23]. One unit of activity is defined as the formation of $1 \mu \mathrm{mol}$ product $\mathrm{min}^{-1}$ at $30^{\circ} \mathrm{C}$. One unit of GST activity is defined as the amount of enzyme which catalyzes the formation of 1.0 $\mu$ mole of thioether per min.

\subsubsection{Glutathione Reductase (GR)}

The GR activity was determined spectrophotometrically at $25^{\circ} \mathrm{C}$ following the decrease in absorbance at $340 \mathrm{~nm}$ according to the method described by Zanetti [24].

\subsubsection{Glutathione Peroxidase (GPx)}

GPx was measured spectrophotometrically at $25^{\circ} \mathrm{C}$ according to the method described by Weinhold et al. [25]. One unit of GPx and GR activity is defined as the amount of enzyme, which oxidize $1 \mu$ mole of NADPH $\left(\varepsilon_{340}=6.22\right.$ $\mathrm{mM}^{-1} \mathrm{~cm}^{-1}$ ) per min.

\subsubsection{Catalase (CAT)}

The CAT activity was assayed according to the method described by Aebi [26]. The method is based on monitoring the rate of decomposition of $\mathrm{H}_{2} \mathrm{O}_{2}$ at $25^{\circ} \mathrm{C}$. One unit of activity was defined as the calculated consumption of $1 \mu \mathrm{mol}$ of $\mathrm{H}_{2} \mathrm{O}_{2}\left(\varepsilon 340=43.6 \mathrm{mM}^{-1} \mathrm{~cm}^{-1}\right)$ per min.

\subsubsection{Superoxide Dismutase (SOD)}

The SOD activity was determined using a commercial kit purchased from Biodiagnostic (Cat. No. SD 25 21) based on the method described by Nishikimi et al. [27]. One unit of enzyme activity is defined as the amount of enzyme that gave $50 \%$ inhibition of nitroblue tetrazolium reduction in one minute. Specific activity of all antioxidant enzymes is expressed as unit/mg protein.

\subsection{Effect of $\mathrm{pH}$}

Activity of purified GST fractions were assayed at different $\mathrm{pH}$ ranges using $0.1 \mathrm{M}$ citrate phosphate buffer for $\mathrm{pH}$ ranged from 4.5 to $6,0.1 \mathrm{M}$ potassium phosphate buffer for $\mathrm{pH}$ ranged from 6 to 7.5 , and $0.1 \mathrm{M}$ Tris- $\mathrm{HCl}$ buffer for $\mathrm{pH}$ ranged from 7.5 to 10 .

\subsection{Kinetic Parameters}

Kinetic measurements were performed at $25^{\circ} \mathrm{C}$ in $0.1 \mathrm{M}$ potassium phosphate buffer, $\mathrm{pH}$ 6.5. The concentration of CDNB was varied between $0.1-2 \mathrm{mM}$ at constant concentration of GSH of $5.0 \mathrm{mM}$. The GSH concentration was varied between 0.1 and $2.0 \mathrm{mM}$ at constant concentration of CDNB of $2.0 \mathrm{mM}$. The $\mathrm{K}_{\mathrm{m}}$ and $\mathrm{V}_{\max }$ values were calculated by using the Michaelis-Menten equation in GraphPad Prism 5 soft ware (GraphPad Prism Soft ware Inc., USA).

\subsection{Inhibition Studies}

The $\mathrm{IC}_{50}$ value of each inhibitor (hematin, cibacron blue, sulfobromophthaliene and EA) for T. alexandrinum dry and germinated seeds GST was determined according to Yalcin et al. [28].

\subsection{Statistical Analysis}

The Student's t-test was performed to examine the difference between means. Experimental results were mentioned as mean \pm SD of three parallel measurements. $P$ values $<0.05$ were regarded as significant, $p$ values $<0.01$ as highly significant and $p$ values $>0.05$ as insignificant.

\section{Results}

\subsection{Changes in the Total Phenolic, Flavonoid Contents and Antioxidant Capacity during T. Alexandrinum Seed Germination}

Total phenolics, total flavonoids and antioxidant capacity in $70 \%$ ethanolic extract of dormant and germinated seeds were determined (Table 1). The highest phenolic and flavonoid content was found in $T$. alexandrinum dormant seeds. This was followed by significant decrease $(P<0.001)$ by day 4 and 6 . The highest antioxidant capacity was observed in dormant seeds and significantly increased by 2 days of germination $(P>0.001)$.

Table 1. Total phenolic, total flavonoid contents ( $\mathrm{mg} / \mathrm{g}$ dry seeds) and antioxidant capacity ( $\mathrm{mg}$ dry weight/g dry seeds) of ethanolic extract of dormant and germinated T. alexandrinum seeds.

\begin{tabular}{llll}
\hline T. alexandrinum & Phenolics & Flavonoids & IC $_{\mathbf{5 0}}$ \\
\hline Dormant seeds & $64 \pm 7.5$ & $19.2 \pm 1.0$ & $1.27 \pm 0.06$ \\
Germinated seeds & & & \\
2 days & $50.3 \pm 2.5$ & $4.70 \pm 0.3 * *$ & $2.70 \pm 0.30 * *$ \\
4 days & $41 \pm 1.0 * *$ & $6.60 \pm 0.6 * *$ & $3.30 \pm 0.30^{* *}$ \\
6 days & $41.7 \pm 1.1 * *$ & $7.80 \pm 0.6^{* *}$ & $3.30 \pm 0.15^{* *}$ \\
\hline ** Highly significant $P<0.001$ & &
\end{tabular}

\subsection{Effect of Germination on Seed Antioxidant Enzyme Activities}

The final germination percentage of the $T$. alexandrinum dormant seeds after 6 days was over 95\%. The crude homogenate of T. alexandrinum dormant and 2, 4 and 6 days 
old germinated seeds was prepared as previously described in the materials and methods section. The total protein content was decreased during seed germination stages. The total protein content of dormant seeds (46 $\mathrm{mg} / \mathrm{g}$ tissue) was decreased to $6.95 \mathrm{mg} / \mathrm{g}$ tissue in six days old germinating seeds. The catalytic activity of GST, GR, GPx, CAT and SOD were assayed in the crude homogenates of dormant as well as 2, 4 and 6 days old germinated seeds (Table 2). In opposite to other enzymes, GST was significantly decreased $(P<0.001)$ by germination while the other examined antioxidant enzymes were significantly increased by germination.

Table 2. Antioxidant Enzyme Activities of T. Alexandrinum Seeds during Germination.

\begin{tabular}{|c|c|c|c|c|c|c|}
\hline \multirow[b]{2}{*}{ T. alexandrinum } & \multirow{2}{*}{ Protein (mg/g tissue) } & \multicolumn{5}{|c|}{ Specific activity (Unit /mg protein) } \\
\hline & & GST & CAT & SOD & GPx & GR \\
\hline Dormant seeds & $46.4 \pm 4.80$ & $0.35 \pm 0.02$ & $31.2 \pm 2.8$ & $5 \pm 0.50$ & ND & $0.01 \pm 0.001$ \\
\hline \multicolumn{7}{|l|}{ Germinated seeds } \\
\hline 2 days & $20.1 \pm 2.9$ & $0.15 \pm 0.01 *$ & $122 \pm 21 *$ & $28 \pm 3 *$ & $0.05 \pm 0.006^{*}$ & $0.01 \pm 0.001$ \\
\hline 4 days & $11.7 \pm 0.50$ & $0.11 \pm 0.007 *$ & $90 \pm 7.2 *$ & $27 \pm 2.5^{*}$ & $0.05 \pm 0.004 *$ & $0.02 \pm 0.002 *$ \\
\hline
\end{tabular}

* Highly significant $\mathrm{P}<0.001$.

ND: not detected under the experimental conditions

\subsection{GST Purification and Molecular Weight Determination}

Simple reproducible procedures for the purification of GST from dormant (46 units \& $365 \mathrm{mg}$ protein) and germinated (16.2 units \& $164 \mathrm{mg}$ protein) T. alexandrinum seeds are summarized in Tables $3 \& 4$. The procedure included ion exchange chromatography on DEAE-Sepharose followed by gel filtration on Sephadex G-100. The specific activity of dormant GST2 and germinated GST3 increased to 3.3 and 0.85 unit $/ \mathrm{mg}$ protein after gel filtration on Sephadex G-100, respectively. Typical elution profiles for the chromatography of $T$. alexandrinum dormant and germinated crude homogenates on DEAE-Sepharose are shown in Fig. 1 $\mathrm{a}, \mathrm{b}$. The bound proteins were eluted with buffer A containing stepwise gradients of $\mathrm{NaCl}(0.05,0.1$ and $0.2 \mathrm{M})$ at a flow rate of $60 \mathrm{ml} / \mathrm{h}$. Three protein peaks with GST activity were eluted with $0.05,0.1$ and $0.2 \mathrm{M} \mathrm{NaCl}$. The GST containing fractions under each peak were pooled separately and designated GST1, GST2 and GST3 for dormant seeds and germinated GST1, GST2 and GST3 for germinated seeds according to their elution order, respectively. The specific activity of the major GST peaks of dormant GST2 and germinated GST3 of T. alexandrinum seeds was changed to
$0.85 \& 0.09 \mu \mathrm{mol} / \mathrm{min} / \mathrm{mg}$ protein with an overall recovery of $88 \%$ \& 41.7\%, respectively (Table $3 \& 4$ ). The molecular weight of dormant GST2 and germinated GST3 was calculated from Sephadex G-100 calibrated curve to be 52.5 and $47.8 \mathrm{KDa}$, respectively (Fig. 2).

T. alexandrinum crude homogenate and DEAE-Sepharose purified fractions (GST1, GST2 and GST3) were applied to native-PAGE and stained for activity (Fig. 3). PAGE of $T$. alexandrinum crude homogenate indicated the presence of three main GST activity spots, GST1, GST2 and GST3 exhibited low, medium and high relative mobility, respectively.

Subunit molecular weights of $T$. alexandrinum dormant seeds GST2 and germinated seeds GST3 were estimated using $12 \%$ SDS-PAGE and the molecular weight was calculated from previously established standard curve for known molecular weight proteins. T. alexandrinum GST2 dormant seed was found to be a heterodimer with subunit molecular weight of 27.5 and $28.5 \mathrm{KDa}$ while GST3 germinated seeds was a homodimer with molecular weight of 27.0 KDa (Fig. 4).

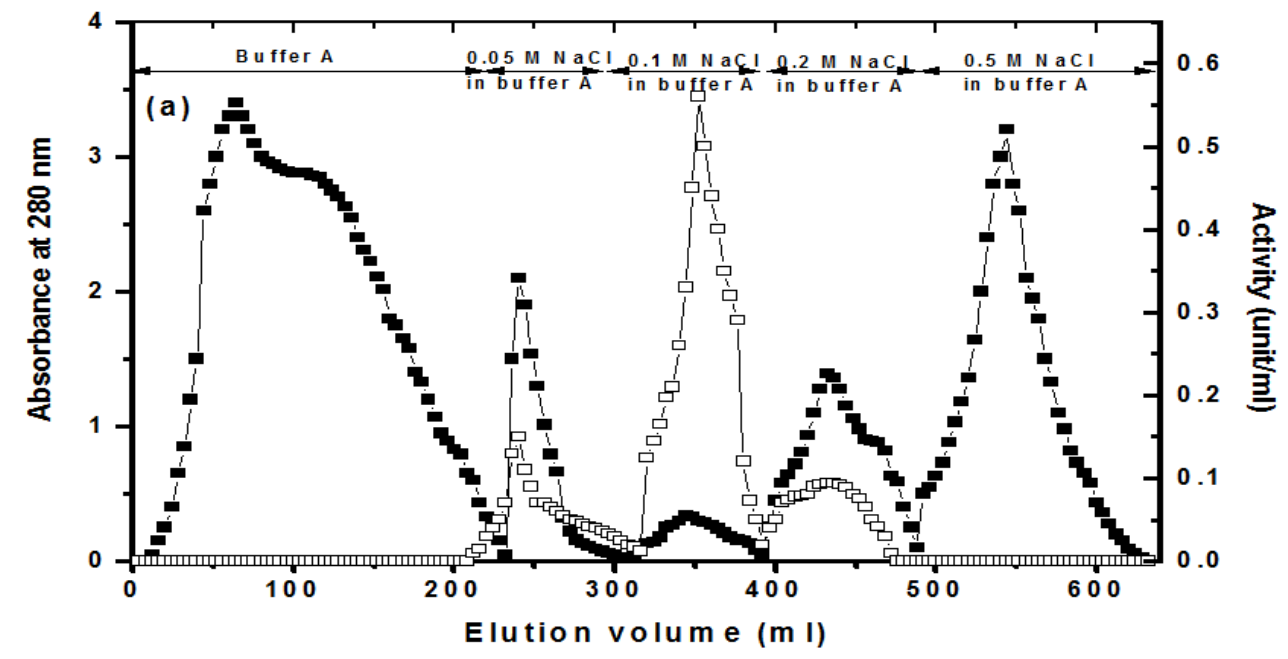




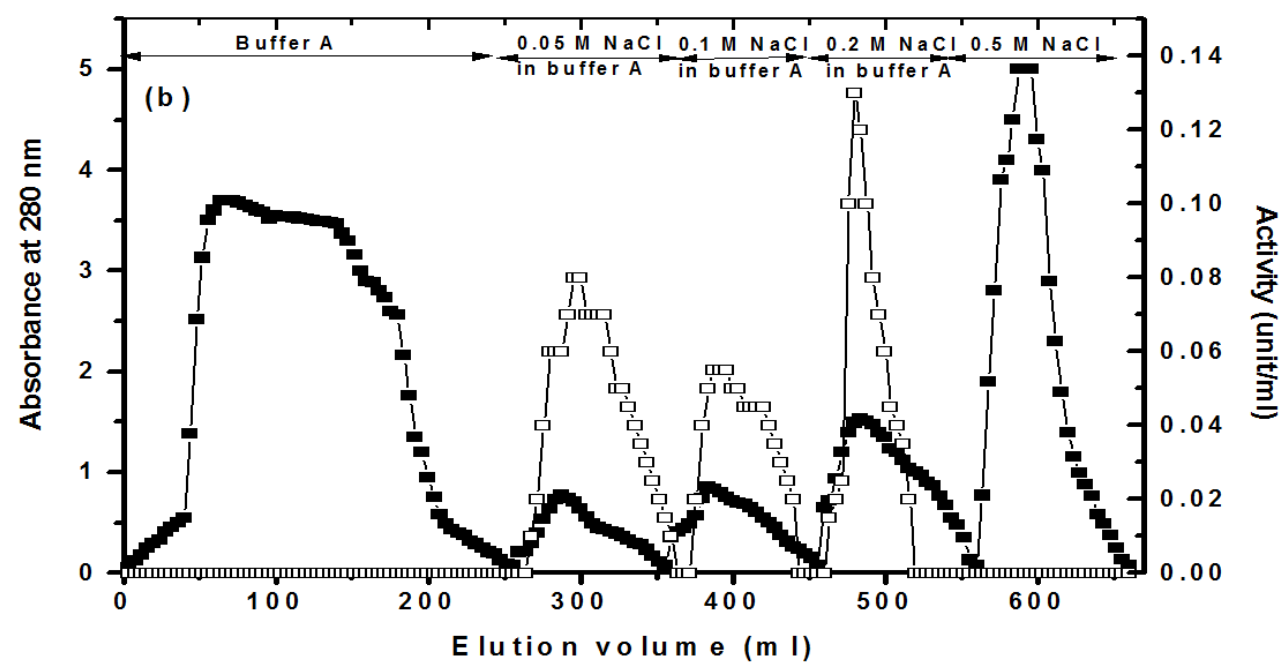

Fig. 1. Typical elution profiles of T. alexandrinum dormant (a) and germinated (b) seeds on DEAE-Sepharose column. Absorbance at $280 \mathrm{~nm}(\cdot)$ and GST activity at $340 \mathrm{~nm}$ (ㅁ).
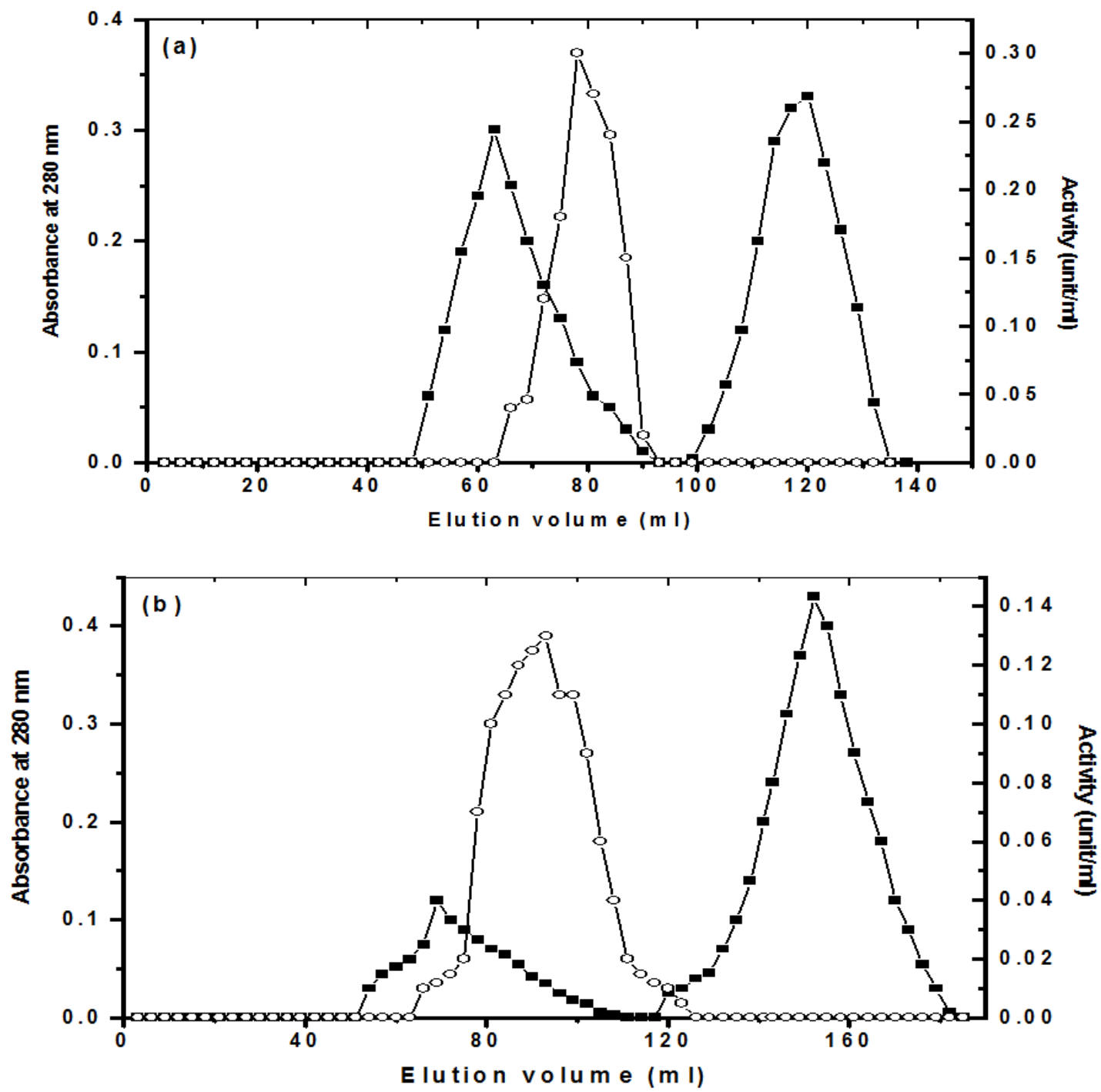

Fig. 2. Typical elution profiles for the chromatography of T. alexandrinum of dormant GST2 (a) and germinated GST3 (b) seeds on Sephadex G-100 column at a flow rate of $20 \mathrm{ml} / \mathrm{h}$ and $3 \mathrm{ml}$ fractions volume. Absorbance at $280 \mathrm{~nm}(\cdot)$, GST activity at $340 \mathrm{~nm}(\mathrm{o})$. 


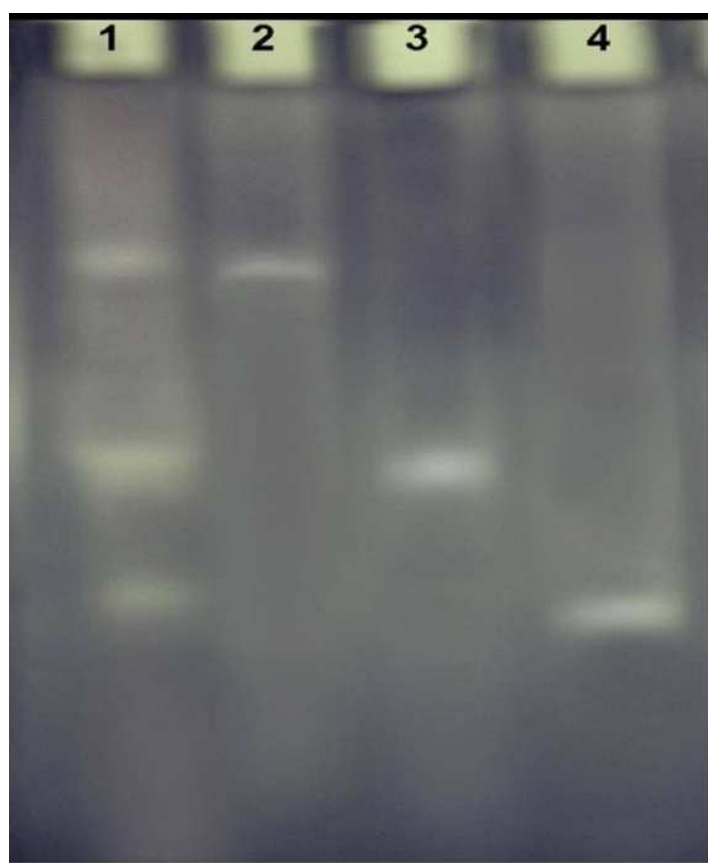

Fig. 3. Native PAGE of DEAE-Sepharose column fractions stained for GST activity using CDNB as substrate. Crude homogenate (1) and DEAE-Sepharose column fractions: GST1 (2), GST2 (3), and GST3 (4).

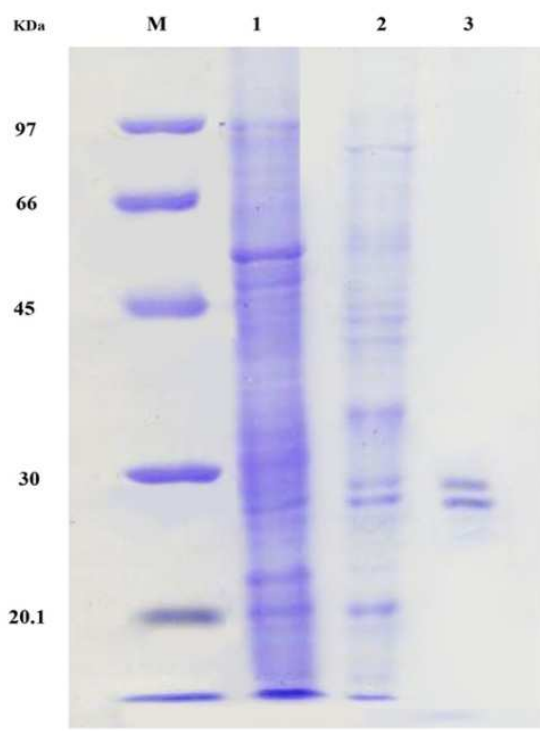

(a)

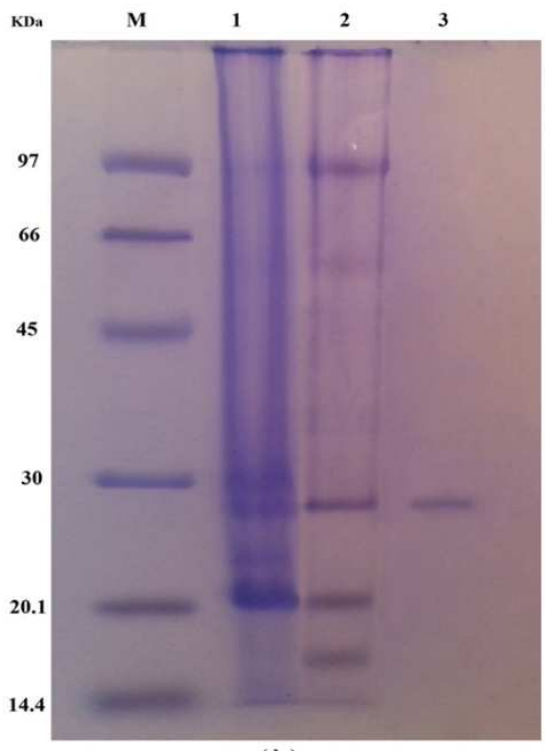

(b)

Fig. 4. SDS-PAGE (12\%) of dormant GST2 (a) and germinated GST3 (b) stained for protein by Coomassie brilliant blue R-250. Standard low molecular weight markers (M), crude homogenate (1), DEAE-Sepharose fraction (2), gel filtration fraction (3).

Table 3. Purification scheme of GST of dormant T. alexandrinum seeds.

\begin{tabular}{|c|c|c|c|c|c|}
\hline T. alexandrinum & Activity (units) & Protein (mg) & Specific activity* & Recovery (\%) & Fold purification \\
\hline Dormant seeds & 46 & 365 & 0.12 & 100 & 1 \\
\hline \multicolumn{6}{|l|}{ DEAE-Sepharose } \\
\hline GST1 & 4.1 & 12.1 & 0.33 & 9 & 2.75 \\
\hline GST2 & 36 & 42 & 0.85 & 78 & 7.08 \\
\hline GST3 & 0.6 & 55 & 0.01 & 1 & 0.09 \\
\hline \multicolumn{6}{|c|}{ Sucrose concentration } \\
\hline \multicolumn{6}{|l|}{ Gel filtration } \\
\hline GST2 & 12 & 3.6 & 3.3 & 26 & 27.5 \\
\hline
\end{tabular}

* Specific activity was expressed in $\mu$ mole $/ \mathrm{min} / \mathrm{mg}$ protein. 
Table 4. Purification scheme of GST from 6 days old germinated T. alexandrinum seeds

\begin{tabular}{llllll}
\hline T. alexandrinum & Activity (units) & Protein $(\mathbf{m g})$ & Specific activity* & Recovery (\%) & Fold purification \\
\hline Germinated seeds & 16.2 & 164 & 0.09 & 100 & 1 \\
DEAE-Sepharose & & & & & \\
GST1 & 2.16 & 4.2 & 0.51 & 13.3 & 5.7 \\
GST2 & 1.93 & 2.9 & 0.67 & 12 & 7.4 \\
GST3 & 2.63 & 29 & 0.09 & 16.2 & 2.0 \\
Sucrose concentration & & 10 & 0.25 & 15.6 & \\
GST3 & 2.5 & & & & \\
Gel filtration & & 1 & 0.85 & 5.32 & 10 \\
GST3 & 0.85 & & & \\
\hline
\end{tabular}

* Specific activity was expressed in $\mu$ mole $/ \mathrm{min} / \mathrm{mg}$ protein.

\subsection{Characterization of Purified Dormant and Germinated GST Isoenzymes}

\subsubsection{Effect of $p H$}

The effect of $\mathrm{pH}$ on the activity of GST1 and GST2 isoenzymes of dormant seed as well as GST2 and GST3 of germinated seed of T. alexandrinum was examined. Dormant GST1 exhibited a sharp optimum $\mathrm{pH}$ at 7.0 while dormant GST2 exhibited a bell shape optimum $\mathrm{pH}$ between $\mathrm{pH}$ 7.07.5 (Fig. 5 a, b). On the other hand, the germinated GST2 and GST3 exhibited a sharp optimum pH at pH 8.0 (Fig. 5 c, d).
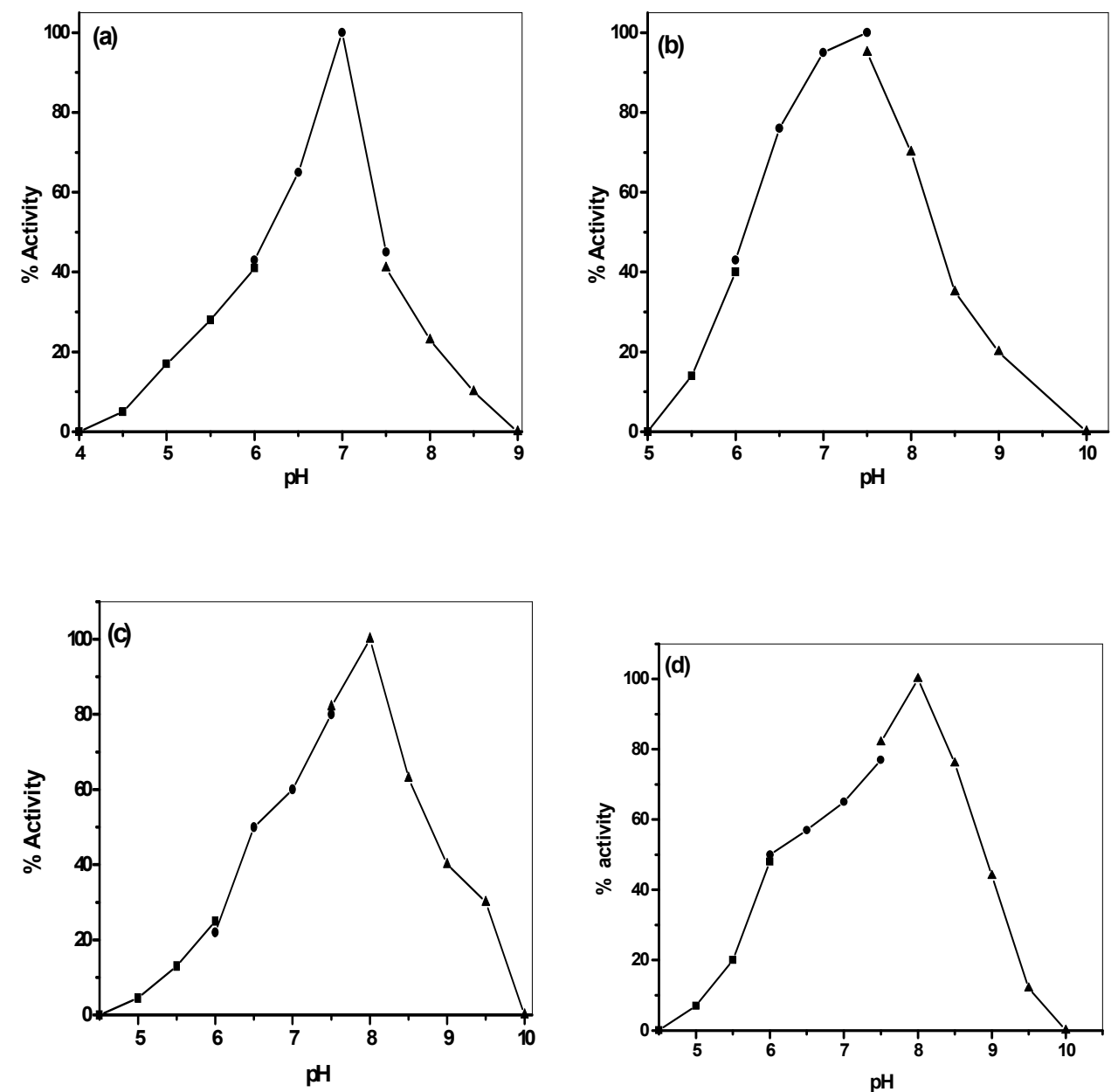

Fig. 5. Effect of pH on T. alexandrinum dry seeds GST1 (a), GST2 (b) and germinated seeds GST2 (c), GST3 (d). The maximum activity was expressed as 100\%. $0.1 \mathrm{M}$ citrate phosphate buffer (•), $0.1 \mathrm{M}$ sodium phosphate buffer (•), and $0.1 \mathrm{M}$ Tris-HCl buffer (4). 


\subsubsection{Substrate Selectivity}

Germinated and dormant GST isoenzymes did not show any detectable activity toward NPB, EPNP, SO and DCNB with the exception of germinated GST3, GST activity could be detected on EA. Germinated GST3 exhibited high activity on EA (73\%). The four isoenzymes exhibited peroxidatic activity toward $\mathrm{CuOOH}$. While dormant GST2 and germinated GST3 exhibited high peroxidatic activity (74 and $76 \%$ ) of the activity on CDNB, dormant GST1 and germinated GST2 exhibited 33 and 28\% (Table 5).

Table 5. GST activity towards different electrophilic substrates.

\begin{tabular}{|c|c|c|c|c|c|c|}
\hline \multirow{2}{*}{ Seeds } & \multicolumn{2}{|l|}{ CDNB } & \multicolumn{2}{|l|}{$\mathrm{CuOOH}$} & \multicolumn{2}{|l|}{ EA } \\
\hline & Specific activity* & \%Relative activity & Specific activity* & \%Relative activity & Specific activity* & $\%$ Relative activity \\
\hline \multicolumn{7}{|c|}{ Dormant } \\
\hline GST2 & $0.47 \pm 0.08$ & 100 & $0.35 \pm 0.02$ & 74 & ND & ND \\
\hline \multicolumn{7}{|c|}{ Germinated } \\
\hline GST2 & $0.75 \pm 0.08$ & 100 & $0.21 \pm 0.03$ & 28 & ND & ND \\
\hline GST3 & $0.10 \pm 0.01$ & 100 & $0.08 \pm 0.01$ & 76 & $0.07 \pm 0.005$ & 73 \\
\hline
\end{tabular}

*Specific activity was expressed in $\mu \mathrm{mol} / \mathrm{min} / \mathrm{mg}$ protein

ND: not detected under the experimental conditions

\subsubsection{Kinetic Parameters}

The $\mathrm{K}_{\mathrm{m}}$ values and $\mathrm{V}_{\max }$ for dormant GST1 and GST2 and germinated GST2 and GST3 are summarized in Table 6 . The $K_{m}$ of CDNB for GST2 is almost the same for both germinated and dormant seeds, while $\mathrm{K}_{\mathrm{m}}$ of CDNB for GST3 is almost double that of GST2 either germinated or dormant seeds (significant increase $p<0.001$ ). $\mathrm{K}_{\mathrm{m}}$ values for GSTs of dormant and germinated for GSH are comparable; the changes in the values are statistically insignificant $(P<0.1)$.

\subsubsection{Inhibition Studies}

Cibacron blue, sulfobromophthaliene, EA and hematin were tested for their ability to inhibit CDNB-conjugating activity of the purified T. alexandrinum dormant GST1, GST2, germinated GST2 and GST3 isoenzymes. $\mathrm{IC}_{50}$ values (Table 7) were determined by measuring the activity of the isoenzyme in the presence of varying concentrations of the inhibitor. The most potent inhibitor for dormant and germinated GSTs is cibacron blue followed by hematin. Dormant GST1 is the most sensitive one for cibacrone blue and hematin with $\mathrm{IC}_{50}$ of 0.23 and $0.65 \mu \mathrm{M}$, respectively while EA is the most potent inhibitor for germinated GST3 but had almost no effect on dormant seed GST1.

Table 6. Kinetic parameters of T. alexandrinum dormant GST1, GST2, germinated GST2 and GST3.

\begin{tabular}{|c|c|c|c|c|}
\hline \multirow{2}{*}{$\begin{array}{l}\text { T. } \\
\text { alexandrinum }\end{array}$} & \multicolumn{2}{|l|}{ GSH } & \multicolumn{2}{|l|}{ CDNB } \\
\hline & $K_{m}(\mathbf{m M})$ & $V_{\text {max }} *$ & $K_{m}(\mathbf{m M})$ & $V_{\text {max }} *$ \\
\hline \multicolumn{5}{|l|}{ Dormant seeds } \\
\hline GST1 & $1.17 \pm 0.39$ & $0.06 \pm 0.009$ & $0.65 \pm 0.095$ & $0.05 \pm 0.003$ \\
\hline GST2 & $1.22 \pm 0.13$ & $0.23 \pm 0.009$ & $0.57 \pm 0.11$ & $0.32 \pm 0.026$ \\
\hline \multicolumn{5}{|l|}{$\begin{array}{l}\text { Germinated } \\
\text { seeds }\end{array}$} \\
\hline GST2 & $0.84 \pm 0.19$ & $0.04 \pm 0.004$ & $0.59 \pm 0.14$ & $0.04 \pm 0.003$ \\
\hline GST3 & $0.96 \pm 0.24$ & $0.16 \pm 0.016$ & $1.02 \pm 0.18$ & $0.13 \pm 0.01$ \\
\hline
\end{tabular}

* $\mathrm{V}_{\max }$ was expressed in $\mu \mathrm{mol} / \mathrm{min} / \mathrm{mg}$ protein.
Table 7. Effect of inhibitors (IC 50 values) on purified T. alexandrinum dormant (GST1, GST2) and germinated (GST2, GST3) seeds.

\begin{tabular}{lllll}
\hline \multirow{2}{*}{ Inhibitor } & \multicolumn{3}{l}{$\mathbf{I C}_{\mathbf{5 0}}(\boldsymbol{\mu M})$} \\
\cline { 2 - 5 } & \multicolumn{2}{l}{ Dormant seed } & Germinated seed \\
\cline { 2 - 5 } & GST1 & GST2 & GST2 & GST3 \\
\hline Hematin & 0.65 & 30 & 20 & 12 \\
Cibacron blue & 0.23 & 7 & 1 & 9 \\
Sulfobromophthaliene & 200 & 50 & 400 & 110 \\
Ethacrynic acid & NI & 100 & 74 & 0.60 \\
\hline
\end{tabular}

NI: No inhibition under the experimental conditions.

\section{Discussion}

The germination process changed the total phenolic and flavonoid contents of legume seeds and their antioxidant capacity were also altered. Our results indicated that $T$. alexandrinum dormant seeds had phenolic contents of $64 \pm 7.5 \mathrm{mg} / \mathrm{g}$ dry seed and flavonoid content of $19.2 \pm 1.12$ $\mathrm{mg} / \mathrm{g}$ dry seed. The ratio of flavonoids to phenolics for the plants used in our study is less than $10 \%$ except for $T$. alexandrinum which has a higher ratio (30\%). Among six Trifolium species examined by Koldziejczyk-Czepas et al. [29], it was found that the aerial parts of T. alexandrinum had the highest contents of phenolic $(52.55 \mathrm{mg} / \mathrm{g}$ dry matter) and flavonoid $(22.30 \mathrm{mg} / \mathrm{g}$ dry matter). Seeds of 57 species of the genus Trifolium have been studied for the occurrence and concentration of flavonoids [30]. All but three tested species contained flavonoids. flavonoid contents in Trifolium species ranged from 0.04 to $8.16 \mathrm{mg} / \mathrm{g}$ dry matter. The majority of species contained quercetin as a sole flavonoid or in the mixture with a number of unidentified flavonoid components. The concentration of quercetin was in the range $0.05-3 \mathrm{mg} / \mathrm{g}$ dry matter in the Trifolium species [31].

Trifolium incarnatum extract was particularly rich in flavonoids $(41.54 \mathrm{mg} / \mathrm{g}$ dry matter), but $T$. alexandrinum 
contained isoflavones (18.97 $\mathrm{mg} / \mathrm{g}$ dry matter) and significant amounts $(9.63 \mathrm{mg} / \mathrm{g}$ dry matter $)$ of clovamides. The interaction between phenolic compounds and DPPH depends on their structural conformation. Phenolics with a high number of hydroxyl groups can react very rapidly and reduce a large number of DPPH molecules [32]. The observed antioxidant effect of Trifolium extracts may be attributed to scavenging of both peroxynitrite and radicals derived from its decomposition [29].

It was found that the total phenolic and flavonoid contents of mature legume seeds significantly decreased after short-term germination. However, their antioxidant capacity increased after long-term germination [33]. In the present study, total phenolic and flavonoid contents were detected by germination period. The concentration of flavonoids was significantly changed after germination and influenced by the varieties and stages of germination. The contents and compositions of bioactive compounds varied greatly between types of legumes and their varieties, due to genetic characteristics. Also the compositions of flavonoids differed in each germination stage of $T$. alexandrinum and the degree of seed germination. This observation is analogous with the results obtained by Lin and Lai [33] but in difference with data obtained by Cevallos-Casals and Cisneros-Zevallos [34] for edible seed species.

Regarding the antioxidant capacity, the germination process modifies the antioxidant activity, measured by its free radical scavenging capacity of $T$. alexandrinum seeds. After a germination of 2, 4, 6 days, seeds show higher antioxidant capacity than dormant seeds. Time may affect the antioxidant activity, as they reach the highest values of antioxidant activity after 6 days of germination. This observation was found to be analogous to peas, beans and lentils [12].

The main detoxifying systems involve enzymes, mainly SOD, CAT and enzymes of the ascorbate glutathione cycle, the antioxidant compounds such as reduced glutathione and ascorbate [35]. However, the efficiency of active oxygen species scavenging through antioxidant enzyme activities, mainly CAT, has been increased during seed development [36]. On the other hand, ascorbate peroxidase (APX) and GR activities decreased during desiccation of Triticum durum seeds [37].

In our study, the dormant seeds exhibited the highest GST activity as compared to the germination stages and this may be due to the biochemical metabolism changes of the seeds during germination, which might produce some secondary plant metabolites such as anthocyanins and flavonoids or release aglycones from conjugated glycosides from seed coats and cotyledons due to the enzymatic activation [38]. These metabolites may inhibit GST activity during germination stages. On the other hand, GR, CAT, SOD and GPx increase during germination stages as compared to dormant seeds.

The DEAE-Sepharose profile for GST activity changed by germination. Although the isoenzyme pattern is almost comparable, where three isoenzyme peaks were observed, they changed in amounts. The GST2 is the major in dormant seeds $(78 \%$ of the total activity) while the germinated GST3 was increased from 1 to $16 \%$ of the total activity by germination. Five GSTs isoenzymes were separated and designated GST1, GST2, GST3, GST4 and GST5 according to their elution order from onion bulb [39].

Our results indicated that germinated GST3 was expressed as homodimer (M.wt. $27 \mathrm{KDa}$ ) while the presence of two subunits with different molecular weight may suggest that dormant GST2 is either a heterodimer (M.wt. 27.5 and $28.5 \mathrm{KDa}$ ) or the presence of more than one protein having slightly different molecular weights. These results are in agreement with the molecular weights reported by Gronwald and Plaisance [40] for sorghum GST in which GST isoenzymes A1/A1 and B1/B2 were purified from sorghum shoots. GST A1/A1, a constitutively expressed as homodimer, had a molecular mass of $26 \mathrm{KDa}$, GST B1/B2 was a heterodimer with subunit molecular masses of $26 \mathrm{KDa}$ for $\mathrm{B} 1$ and $28 \mathrm{KDa}$ for $\mathrm{B} 2$. Also four GSTs were identified in Festuca arundinacea in which GST1 was purified until homogeneity was determined to be a heterodimer consisting of two subunits of 28.0 and 27.2 KDa [41].

In the present investigation, the kinetic studies of the purified T. alexandrinum GSTs exhibited typical MichaelisMenten equation with respect to GSH as substrate. The $\mathrm{K}_{\mathrm{m}}^{\mathrm{GSH}}$ values are ranged from $0.84 \pm 0.19$ to $1.22 \pm 0.13 \mathrm{mM}$ which was in general agreement with published $\mathrm{K}_{\mathrm{m}}^{\mathrm{GSH}}$ values of approximately $0.34-0.84 \mathrm{mM}$ for the Oryza sativa GSTF5 [42]. In contrast, The $\mathrm{K}_{\mathrm{m}}{ }^{\mathrm{CDNB}}$ values of $T$. alexandrinum GST are ranged from $0.57 \pm 0.11$ to $1.02 \pm 0.18$ $\mathrm{mM}$. These values are similar to $\mathrm{K}_{\mathrm{m}}{ }^{\mathrm{CDNB}}$ values reported for the GST of Oryza sativa which calculated to be $0.55 \mathrm{mM}$ [42], Lactuca sativa which calculated to be $1.42 \mathrm{mM}$ [43]. It can be concluded from our results that $\mathrm{K}_{\mathrm{m}}{ }^{\mathrm{CDNB}}$ for GST2 is almost the same for both germinated and dormant seeds; while $\mathrm{K}_{\mathrm{m}}{ }^{\mathrm{CDNB}}$ for GST3 is almost double of GST2 either germinated or dormant seeds $(p<0.0001)$. This indicates that the affinity of GST2 to CDNB of either germinated or dormant is higher than germinated GST3.

The activity of $T$. alexandrinum GSTs toward CDNB was significantly lower than the enzymes from corn and Lactuca sativa which has a value of $4.03 \pm 0.23 \mu \mathrm{mol} / \mathrm{min} / \mathrm{mg}$ protein [43]. Also they showed selenium-independent GPx activity toward $\mathrm{CuOOH}$ as an alternative substrate with specific activity ranged from $0.076 \pm 0.01$ to $0.35 \pm 0.02 \mu \mathrm{mol} / \mathrm{min} / \mathrm{mg}$ protein. The theta-class GSTs purified from Arabidopsis thaliana also exhibited selenium-independent GPx activity of $1.32 \pm 0.01 \mu \mathrm{mol} / \mathrm{min} / \mathrm{mg}$ protein [43]. In the present investigation, GST activity in dormant seeds is significantly higher than that of the 6 days GST, while no GSH peroxidatic activity could be detected. This may suggest that GST2 of dormant seeds is mainly responsible for the GSH peroxidatic activity. However GST activity significantly dropped by germination and GST3 activity increased having high peroxidatic activity beside that GSH peroxidase significantly increased. This role of GST is represented by its function as 
glutathione-dependent peroxidase catalyzing the reduction of oxidative stress products, such as organic hydroperoxides [3]. Beside that the presence of GSTs having peroxidatic activity may have a role in the tolerance to herbicides by effectively scavenging toxic byproducts of herbicide activity and to the protection of the cell from lipid peroxidation [44, 45]. In opposite to other isoenzymes under this investigation, inated seed GST3 exhibited enzymatic activity towards EA with specific activity $0.073 \pm 0.005 \mu \mathrm{mol} / \mathrm{min} / \mathrm{mg}$ protein. However, all T. alexandrinum GST isoenzymes are not significantly active towards DCNB, NPB, SO and EPNP.

In this study, the most potent inhibitor for dormant and germinated GSTs is cibacron blue followed by hematin while EA is the most potent inhibitor for germinated GST3 with $\mathrm{IC}_{50}$ of $0.60 \mu \mathrm{M}$ but had almost no effect on dormant seed GST1. The present data is analogous to the results reported by Gyamfi et al. [46] for Thonningia sanguinea in which the effect of EA is very strong with $\mathrm{IC}_{50}$ of $0.83 \pm 0.04 \mu \mathrm{M}$ and differs from that reported by Jo et al. [47] for Oryza sativa in which the effect of EA is week with $\mathrm{IC}_{50}$ of $268 \pm 19 \mu \mathrm{M}$. The lower $\mathrm{IC}_{50}$ value for EA indicates a higher affinity of $T$. alexandrinum germinated GST3 for electrophilic substrate which is similar to $\mathrm{IC}_{50}$ of $0.28 \pm 0.04 \mu \mathrm{M}$ of Lactuca sativa reported by Park et al. [43]. On the other hand, sulphobromophthaliene was less potent inhibitor among the substances tested with $\mathrm{IC}_{50}$ ranged from 50 to $400 \mu \mathrm{M}$ for both dormant and germinated GSTs.

\section{Conclusion}

The T. alexandrinum was chosen for GST purification and characterization due to its highest GST activity and antioxidant capacity, beside its economical importance. This study is the first report on the purification and characterization of GSTs from T. alexandrinum seeds. The increase in GST3 with different properties from GST2 may consider with the active metabolism that increased by germination and to compensate the increase of ROS and the decrease in phenolics and flavonoids. GR, CAT, SOD and GPx increase during germination stages as compared to dormant seeds. It was shown that GST2 is the major enzyme of the dormant seeds while GST3 was increased in 6 days germinated seeds, which were kinetically different.

\section{References}

[1] Ma ZL and Gao KS. Spiral breakage and photoinhibition of Arthrospira platensis (Cyanophyta) caused by accumulation of reactive oxygen species under solar radiation. Environ Exp Bot 2010; 68: 208-13.

[2] Ribeiro DA and Assis GF. Expression of placental glutathione S-transferase in rat tongue mucosa exposed to cigarette smoke. J Mol Histol. 2008; 39:115-9.

[3] Edwards R, Dixon DP, Walbot V. Plant glutathione $S$ transferases: enzymes with multiple functions in sickness and in health. Trends Plant Sci. 2000; 5:193- 8.
[4] Kampranis SC, Damianova R, Atallah M, Toby G, Kondi G, Tsichlis PN, Makris AM. A novel plant glutathione Stransferase/peroxidase suppresses Bax Lethality in yeast. J Biol Chem. 2000; 38: 29207 - 16.

[5] Cummins I, Wortley DJ, Sabbadin F, He Z, Coxon CR, Straker $\mathrm{HE}$, et al. Key role for a glutathione transferase in multipleherbicide resistance in grass weeds. PNAS. 2015; 110: 5812-17.

[6] Fulkerson WJ, Neal JS, Clark CF, Horadagoda A, Nandra KS, Barchia I. Nutritive value of forage species grown in the warm temperate climate of Australia for dairy cows: grasses and legumes. Livest Sci. 2006; 107: 253- 64.

[7] Mohamed KM, Hassanean HA, Ohtani K, Kasai R, Yamasaki K. Chalcanol glucosides from seeds of Trifolium alexandrinum. Phytochem. 2000; 53: 401- 4.

[8] Shah AS, Ahmed M, Alkreathy HM, Khan MR, Khan RA, Khan S. Phytochemical screening and protective effects of Trifolium alexandrinum (L.) against free radical-induced stress in rats. Food Sci. \& Nutri. 2014; 2: 751- 7.

[9] Butnariu M. An analysis of Sorghum halepense behavior in presence of tropane alkaloids from Datura stramonium extracts. Chem Cent J. 2012; 6: 1-7.

[10] Fransisca L, Park HK, Feng H. E. coli o157: H7 population reduction from alfalfa seeds with malic acid and thiamine dilauryl sulfate and quality evaluation of the resulting sprouts. Food Sci J. 2012; 77: 121-6.

[11] Gaunii A, Pribac G, Grozea L, Gaitin D, Samfira L. Design of optimal solvent for extraction of bio-active ingredients from six varieties of Medicago sativa. Chem. Central J..2012; 6: 123-30.

[12] Lopez-Amoros ML, Hernandez T, Estrella I. Effect of germination on legume phenolic compounds and their antioxidant activity. J Food Comp Anal. 2006; 19: 277- 83.

[13] Cadenas E. Basic mechanisms of antioxidant activity. Biofactors. 1997; 6: 391- 7 .

[14] Valko M, Leibfritz D, Moncol J, Cronin M T D, Mazur M, Telser J. Free radicals and antioxidants in normal physiological functions and human disease. Int $\mathrm{J}$ Biochem Cell Biol. 2007; 39: 44-8.

[15] Singleton VL and Rossi JA. Colorimetry of total phenolics with phosphomolybdic-phospho-tungstic acid reagents. Am j Enol Viticult. 1965; 16: 144- 58.

[16] Woisky R, Salatino A. Analysis of propolis, some parameters and procedure for chemical quality control. J Agricul Res. 1998; 37: 99-105.

[17] Blois M S. Antioxidant determination by the use of stable free radical. Nature. 1985; 181:1199- 200.

[18] Oberg B and Philipson L. Gel filtration of nucleic acids on sphere-condenesd agarose. Arch Biochem Biophys. 1967; 119: 504- 9.

[19] Bradford M M. A rapid and sensitive method for the quantization of microgram quantities of protein utilizing the principal of protein-dye-binding. Anal Biochem.1976; 72: 248- 54.

[20] Laemmli U K. Cleavage of structural proteins during the assembly of the head of bacteriophage T4. Nature. 1970; 227: 680- 5. 
[21] Habig W H, Pabst M J, Jakoby W B. Glutathione STransferase. J Biol Chem. 1974; 249: 7130- 9.

[22] Lawrence R A and Burk R F. Glutathione peroxidase activity in selenium-deficient rat liver. Biochem Biophys Res Commun. 1976; 71: 952- 8

[23] Ivarsson Y, Mackey AJ, Edalat M, Pearson WR, Mannervik B. Identification of residues in glutathione transferase capable of driving functional diverstification in evolution: a novel approach to protein redesign. J Biol Chem. 2003; 278: 8733- 8 .

[24] Zanetti G. Rabbit liver glutathione reductase, purification and properties. Arch Biochem Biophys. 1979; 198: 241- 6.

[25] Weinhold L C, Ahmad S, Pardini R S. Insect glutathione $S$ transferase: A predictor of allelochemical and oxidative stress. Comp Biochem Physiol. 1990; 95 B: 355- 63.

[26] Aebi H. Catalase in vitro. Methods in Enzymol. 1984; 105:121- 6 .

[27] Nishikimi M, Roa N A, Yogi K. Measurement of superoxide dismutase. Biochem Biophys Res Commun. 1972; 46: 849- 54

[28] Yalcin S, Jensson H, Mannervik B. A set of inhibitors for discrimination between the basic isozymes of glutathione transferase in rat liver. Biochem Biophys Res Commun. 1983; 114: 829- 34

[29] Koldziejczyk-Czepas J, Nowak P, Kowalska I, Stochmal A. Biological activity of clovers-free radical scavenging ability and antioxidant action of six Trifolium species. Pharmaceu Biol. 2014; 52: 1308- 14.

[30] Oleszek W and Stochmal A. Triterpene saponins and flavonoids in the seeds of Trifolium species. Phytochem. 2002; 61:165-70.

[31] Sabudak T and Guler N. Trifolium L. A review on its phytochemical and pharmacological profile. Phytother Res.2009; 23: 439- 46.

[32] Vadivel V, Stuetz W, Scherbaum V, Biesalski K H. Total free phenolic content and health relevant functionality of Indian wild legume grains: Effect of indigenous processing methods. J Food Comp Anal. 2011; 24: 935- 43.

[33] Lin P Y and Lai H M. Bioactive compounds in legumes and their germinated products. J Agricul Food Chem. 2006; 54: 3807- 14 .

[34] Cevallos-Casals B A and Cisneros-Zevallos L. Impact of germination on phenolic content and antioxidant activity of 13 edible seed species. Food Chem. 2010; 119: 1485-90.

[35] Scandalios J. Molecular genetics of superoxide dismutases in plants. In: Scandalios J, editor. Oxidative stress and the molecular biology of antioxidant defenses. New York: Cold Spring Harbor Laboratory Press; 1997; pp: 527- 68.
[36] Bailly C, Leymarie J, Lehner A, Rousseau C D, Corbineau F. Catalase activity and expression in developing sunflower seeds as related to drying. J. Exp. Bot. 2004 ; 55: 475- 83.

[37] Lehner A, Mamadou N, Poels P, Come D, Bailly C, Corbineau F. Changes in soluble carbohydrates, lipid peroxidation and antioxidant enzyme activities in the embryo during ageing in wheat grains. J. Cereal Sci. 2008; 47: 555- 65 .

[38] Randhir R., Lin Y T, Shetty K. Stimulation and phenolics, antioxidant and antimicrobial activities in dark germinated mung bean sprouts in response to peptide and phytochemical elicitors. Process Biochem. 2004; 39: 637- 47.

[39] Rohman M M, Suzuki T, Fujita M. Identification of a glutathione S-transferase inhibitor in onion bulb (Allium cepa L.). Aust J Crop Sci. 2009; 3: 28-36.

[40] Gronwald J W, Plaisance KL. Isolation and characterization of GST isozymes from sorghum. Plant Physiol. 1998; 117: 87792

[41] Buono D D, Scarponi L, Espen L. Glutathione $S$-transferases in Festuca arundinacea: Identification, characterization and inducibility by safener benoxacor. Phytochem. 2007; 68: 2614- 24.

[42] Cho H Y, Lee H J, Kong K H. A Phi class glutathione $S$ transferase from Oryza sativa (OsGSTF5): molecular cloning, expression and biochemical characteristics. Biochem. Mol. Biol. 2007; 40: 511-516.

[43] Park H-J, Cho H-Y, Kong K-H. Purification and biochemical properties of glutathione S-transferase from Lactuca sativa. J. Biochem Mol Biol. 2005; 38: 232-237.

[44] Cummins I, O’Hagan D, Jablonkai I, Cole D J, Hehn A, Werck-Reichhart D, Edwards R, Cloning R. Characterization and regulation of a family of Phi class glutathione transferases from wheat. Plant Mol Biol. 2003; 52: 591-603.

[45] Benekos K, Kissoudis C, Nianiou-Obeidat I, Labrou N, Madesis P, Kalamaki M, et al. Overexpression of a specific soybean GmGSTU4 isoenzyme improves diphenyl ether and chloroacetanilide herbicide tolerance of transgenic tobacco plants. J Biotechnol.. 2010; 150: 195-201.

[46] Gyamfi M A, Aniya Y, Ohtani I I, Shinno E. Inhibition of glutathione $S$-transferase by thonningianin A, isolated from the African medicinal herb, Thonningia sanguinea in vitro. Food Chem Toxicol. 2004; 42: 1401- 8.

[47] Jo H J, Lee J J, Kong K H. A plant-specific tau class glutathione $S$-transferase from Oryza sativa with very high activity against 1-chloro-2,4-dinitrobenzene and chloroacetanilide herbicides. Pest Biochem Physiol. 2011; 101: 265-9. 